\title{
Toxoplasmosis Preventive Behavior and Related Knowledge among Saudi Pregnant Women: An Exploratory Study
}

\author{
Tarek Tawfik Amin ${ }^{1}$, Mohamed Nabil Al Ali ${ }^{2}$, Ahmed Abdulmohsen Alrashid ${ }^{2}$, Amena Ahmed Al-Agnam² \& \\ Amina Abdullah Al Sultan ${ }^{3}$ \\ ${ }^{1}$ Faculty of Medicine, Cairo University, Cairo, Egypt \\ ${ }^{2}$ College of Medicine, King Faisal University, Al-Ahsa, Saudi Arabia \\ ${ }^{3}$ Local Health Directorate, Primary Health Section, Ministry of Health, Al Hassa, Saudi Arabia \\ Correspondence: Tarek Tawfik Amin, Associate Professor, Community Medicine and Public Health, Faculty of \\ Medicine, Cairo University, Cairo, Egypt. E-mail: amin55@myway.com
}

Received: May 19, 2013 Accepted: June 19, 2013 Online Published: June 21, 2013

doi:10.5539/gjhs.v5n5p131 URL: http://dx.doi.org/10.5539/gjhs.v5n5p131

\begin{abstract}
Introduction: Many cases of congenital toxoplasmosis can be prevented provided that pregnant women following hygienic measures to avert risk of infection and to reduce severity of the condition if primary prevention failed.
\end{abstract}

Objectives: This descriptive exploratory study aimed to assess the risk behavior and knowledge related to toxoplasmoisis among Saudi pregnant women attending primary health care centers (PHCs) in Al Hassa, Saudi Arabia and to determine socio-demographic characteristics related to risk behavior and knowledge.

Methods: All Saudi pregnant women attending antenatal care at randomly selected six urban and four rural PHCs were approached. Those agreed to participate were interviewed using a pre-tested structured questionnaire collecting data regarding socio-demographic, obstetric history, toxoplasmosis risk behaviors and related knowledge.

Results: Of the included pregnant women, 234 (26.8\%) have fulfilled the criteria for toxoplasmosis preventive behavior recommended by Centers for Disease Prevention and Control to prevent congenital toxoplasmosis, while $48.9 \%$ reported at least one risk behavior and $24.3 \%$ reported $\geq$ two risk behaviors. Logistic regression model revealed that pregnant women aged 20 to $<30$ years and those with previous history of unfavorable pregnancy outcome were more likely to follow toxoplasmosis preventive behavior. Toxoplasmosis-related knowledge showed that many women had identified the role of cats in disease transmission while failed to identify other risk factors including consumption of undercooked meats, unwashed fruits and vegetables, and contacting with soil. Predictors for pregnant women to be knowledgeable towards toxoplasmosis included those aged 30 to $<40$ years $(\mathrm{OR}=1.53)$, with $\geq$ secondary education $(\mathrm{OR}=1.96)$, had previous unfavorable pregnancy outcomes $(\mathrm{OR}=1.88)$ and investigated for toxoplasmosis $(\mathrm{OR}=2.08)$ as reveled by multivariate regression model.

Conclusion: Pregnant women in Al Hasas, Saudi Arabia, are substantially vulnerable to toxoplasmosis infection as they are lacking the necessary preventive behavior. A sizable portion have no sufficient knowledge for primary prevention of congenital toxoplasmosis, health education at primary care is necessary to avert the potential toxoplasmosis related complications especially in the neonates.

Keywords: toxoplasmosis, risk factors, preventive behavior, knowledge, pregnant women, Saudi Arabia

\section{Introduction}

Toxoplasmosis is a disease caused by an obligate intracellular protozoan parasite Toxoplasma gondii (Dubey, 2010). It is estimated that about one third of the World's population is infected with toxoplasmosis (Pappas et al., 2009). High prevalence of infection has been reported among pregnant women and women of childbearing age from different parts of the world including the Middle East (Pappas et al., 2009). In Saudi Arabia, the prevalence of infection showed wide variations as reveled from previous studies at different parts of the Kingdom. The highest positivity rate was reported in Jeddah 61.4\% (Tonkal, 2008), Al Hassa of 51.4\% (Al-Mohammed et al., 2010), and 35.6\% in Makkah (Al-Harthi et al., 2006). Pregnant women with acute infection are at risk of congenitally transmitting the infection to the fetus (Lopez et al., 2000). Congenital toxoplasmosis is a rare condition, with low 
estimate but it can cause severe manifestations ranged from miscarriage to microcephaly, hydrocephalus, seizures, mental retardation and chorioretinitis (Cook et al., 2000). There is lack of information about the incidence of congenital toxoplasmosis in Saudi Arabia. Abdalla et al. (1995) found IgM positivity of $23.1 \%$ among the examined premature Saudi infants. In United Arab Emirates, Dar et al. (1997) have found an estimated prevalence of congenital toxoplasmosis of 12/1000 live births. In view of the asymptomatic nature of toxoplasmosis in adults and its high seroprevalence, primary prevention might decrease the likelihood of congenital toxoplasmosis (Baril et al., 1999). Several studies have addressed the contribution of various risk factors to toxoplasmosis seroconversion during pregnancy. These studies have found that the most significant risk factor to be undercooked meat consumption (Baril et al., 1999; Bobic et al., 1998; Bobic et al., 1996; Kravetz \& Federman, 2005). One study estimated that up to $63 \%$ of the seroconversions during pregnancy was secondary to undercooked meat consumption (Jones et al., 2001), soil contact via gardening, eating raw or unwashed vegetables and fruits (Bobic et al., 1998; Bobic et al., 1996), contact with cat's litter and infrequent washing of kitchen knives used to cut raw meat (Bobic et al., 1998; Bobic et al., 1996; Kravetz \& Federman, 2005). Centers for Diseases Control and Prevention (CDC) recommended the adoption of individual measures for primary prevention of toxoplasmosis during pregnancy, based the preventive behavior directed to food hygiene (Lopez et al., 2000). Nearly all studies that tackled toxoplasmosis among Saudi pregnant women estimated the prevalence of infection and its determinant factors (Tonkal, 2008; Al-Mohammed et al., 2010; Al-Harthi et al., 2006), while none have reported toxoplasmosis preventive behavior. Furthermore, studies assessed the state of toxoplasmosis-related knowledge among pregnant women in Saudi Arabia do not exist, such data are needed for initiating health education activities and aid in the control measures against congenital toxoplasmosis, especially in the absence of routine serological screening program. Dissemination of appropriate knowledge to prevent infection is necessary especially for those most vulnerable namely pregnant women. In a Belgian study it was found that health education was associated with a $63 \%$ reduction in toxoplasmosis seroconversion (Foulon et al., 1994). The objectives of this study were to assess the risk behavior and knowledge related to toxoplasmoisis among Saudi pregnant women attending primary health care centers (PHCs) in Al Hassa, Saudi Arabia and to determine socio-demographic characteristics related to risk behavior and knowledge.

\section{Methods}

\subsection{Setting}

This exploratory descriptive study was carried out in Al Hassa Governorate, Eastern Province of Saudi Arabia; 450 $\mathrm{km}$ from capital Riyadh, and populated by about 1.5 million, composed of three regions; urban, populated by about $60 \%$ of the total population, rural (23 villages with $35 \%$ of the population) and "Hegar" Bedouin scattered communities making up the remaining $5 \%$.

\subsection{Sampling}

Epi-Info version 2002 (CDC, Atlanta, GA, U.S.A.) was used to calculate the sample size required. Pilot study reveled that $27 \%$ of pregnant women attending a nearby two PHCs $(n=47)$ were adopting toxoplasmosis preventive behavior. Considering that the number of pregnant women registered for antenatal care in Al Hassa of 53778 (Local Health Directorate, 2011), with the worst acceptable level of preventive behavior of $23 \%$, a minimal sample size of 500 were required, $20 \%$ were added for the possibility of none response, a total sample size of 610 pregnant were to be included, sampling fraction was employed for selection of subjects in relation to urban/rural distribution. Multistage sampling technique was employed, first, six urban and four rural PHCs were randomly chosen from an updated list (Hegar areas were excluded for transportation problems) and within each PHC all Saudi pregnant women attending for antenatal care from December 1st 2011 to May 31st 2012 were approached. Of the invited women (593 urban and 498 rural), 484 urban and 459 rural women agreed to participate.

\subsection{Data Collection}

Arabic speaking trained nurse at each PHC collected the data through a semi-structured interview including information regarding:

Socio-demographics: Age, residence, educational and occupational status, family income, maid in the house, number of living children, history of pregnancy wastage (abortions and intrauterine fetal deaths, IUFDs), number of pregnancies, and duration of the current pregnancy.

The second part of the interview included inquires about toxoplasmosis preventive behavior as recommended by Centers for Disease Control and Prevention and others (Lopez et al., 2000; Kravetz et al., 2005; Jones et al., 2001) for preventing congenital infection: Consumption of undercooked/partially cooked meat and its frequency in the last week before the interview, consumption of unwashed (and/or unpeeled) fruits and vegetables and their 
frequency in the last week, contacting with soil in the form of gardening (and whether with/without gloves), hand washing after gardening and after removal of gloves, sources of drinking water (bottled, wells or others), presence of cat in the house and their number, contacting with stray cats (if any), cleaning of domestic cat's litter, cleaning of kitchen utensils and cutting boards with hot soapy water. The question formats included yes/no and open ended questions.

Finally participants were inquired about toxoplasmosis-related knowledge employing items from the available literature (Kravetz et al., 2005; Jones et al., 2001; Jones et al., 2003) to assess their knowledge regarding epidemiology of the disease, its effect on pregnancy and the preventive measures to avert infection. The provisional questionnaire included four domains with 28 items included general information about the causative agent (4 items), risk factors (5), symptoms and signs (6), congenital toxoplasmosis (6), and preventive measures (7). Closed ended questions were used with true, false and don't know or multiple options formats. For the knowledge section, correct answer assigned one point while incorrect or do not know responses assigned nil. At the end of the interview participants were inquired about their sources of information.

Revision of medical records to assess if women were ever being investigated, diagnosed or treated for toxoplasmosis, verifying the presence and nature of medical comorbidities (if any) and the occurrence of previous abortions and or IUFDs.

\subsection{Pilot Testing}

Initial questionnaire was compiled in English, which was translated into Arabic by two experts, and then back translated into English by another two independent experts to assure validity of constructs to be assessed. This form was tested on pregnant women attending two nearby PHCs $(n=47)$ beyond the sample size to assure appropriateness, reliability, comprehensiveness and understanding by the interviewees. From the pilot testing toxoplasmosis is known among Saudi women as "cats' disease", the previous term was used all through the interview. Items from the initial knowledge-related questions were eliminated following the pilot testing including questions about signs and symptoms, nature of the organism (being protozoa), and time of maximum fetal damage if infection occurs during pregnancy. Elimination of items was done in response to "either total lack of knowledge and/or difficulties in understanding questions by the respondents". Furthermore, based on alpha analysis which also showed low reliability coefficient; deletion of these items increase the internal consistency (Cronback's alpha) from .341 to .613 . The final form consisted of 20 items: transmission ( 8 items), congenital infection (7items), and preventive measures (5 items).

\subsection{Data Analysis}

Total forms eligible for final analysis were 872 , those with missing of $\geq$ two items were discarded $(n=71)$. Data analysis was carried out using SPSS 16.0 (SPSS Inc, Chicago, IL, U.S.A.). For categorical data, frequency, proportions and percentage were used for reporting, Chi square test were used for comparison. For continuous variables, mean and standard deviation were reported and t-test was used for comparison. Pregnant women were categorized as having toxoplasmosis preventive behavior if they were found to fulfill all preventive behaviors recommended by the Centers for Diseases Control and Prevention 2000 to prevent congenital toxoplasmosis. Univariate analysis with reporting of Odds ratio (OR) and 95\% confidence intervals (CI) was used to assess the possible associations of the included socio-demographic and obstetric-related factors with the adoption of toxoplasmosis preventive behavior. Multivariate logistic regression analysis model was generated to detect possible predictors for toxoplasmosis preventive behavior among the included pregnant women (dependent variable) in relation to the included socio-demographic and obstetric variables (independent variables) that were significant at univariate analysis. For the knowledge part, scores were expressed using median, mean and standard deviation and interquartile range (IQR), student, Mann Whitney and Kruslall Wallis tests were used for comparison when indicated. The $75^{\text {th }}$ percentile for the knowledge score was 8 points (out of 20) pregnant women attained a score of $\geq 8$ points were considered as knowledgeable. A second multivariate regression model was generated to determine the possible correlates including socio-demographics, obstetric variables (independent variables) that predict the knowledge state (dependent variable). P value of $<0.05$ was used to indicate statistical significance.

\subsection{Ethical Considerations}

Full orientation of the approached pregnant women about the study purposes was carried out with the emphasis on their right of not to participate. Informed consent forms were obtained and data confidentiality was maintained all though. 


\section{Results}

\subsection{Socio-Demographics and Obstetric Variables}

The age of the included Saudi pregnant women $(n=872)$ ranged from 17 to 48 years, mean of $29.7 \pm 8.4$ years, $51.9 \%$ of them were urban, with illiteracy rate of $11.9 \%$, educational status was higher among urban compared to rural women $(\mathrm{P}=0.001), 23.3 \%$ were in paid employments, family income was significantly higher in urban compared to rural women $(\mathrm{P}=0.002)$ and $26.5 \%$ were primigravide. Parity ranged from 0 to 12 with a median of 4.0 , number of pregnancy with a median of 4.0 (4.3 \pm 3.1 for urban and $4.1 \pm 3.0$ for rural women). Age at first pregnancy showed a median of 21.0 years (mean of $21.9 \pm 4.4$ years), higher among rural women $(21.6 \pm 3.8$ years in urban vs. $22.2 \pm 5.1$ years in rural). Of the interviewed pregnant women, $45.8 \%$ were in their $1^{\text {st }}, 40.0 \%$ in their $2^{\text {nd }}$ and $16.2 \%$ in their $3^{\text {rd }}$ trimester of pregnancy. Encountered comorbid conditions included hypertension (6.0\%), diabetes mellitus (5.5\%), bronchial asthma (6.2\%), and hemolytic blood diseases including sickle cell disease and thalassemia (more among rural women), 23.6\% reported the presence of maids at houses (106 urban and 110 rural), $68 \%$ reported no previous bad pregnancy outcome (rural was higher the urban), while $32.0 \%$ mentioned the occurrence of previous bad pregnancy outcomes in the form of abortion and/or IUFD, ranged from 1 to 7 . Of the included women $14.2 \%$ were investigated for toxoplasmosis during their previous /current pregnancies (significantly more among rural women), 31 women (4.2\%) were being diagnosed as having toxoplasmosis during their previous pregnancies and $3.6 \%$ (31) had received treatment for infection (Table 1).

Table 1. Socio-demographics of the included pregnant women by residence, Al Hassa, Saudi Arabia

\begin{tabular}{|c|c|c|c|c|}
\hline \multirow{2}{*}{ Characteristics } & \multirow{2}{*}{ Total $(\mathrm{N}=\mathbf{8 7 2})$} & \multicolumn{2}{|c|}{ Residence: No. (\%) } & \multirow{2}{*}{ P value } \\
\hline & & Rural $(\mathrm{N}=419)$ & Urban $(\mathrm{N}=453)$ & \\
\hline Age (years): mean (SD): & $29.7(8.4)$ & $29.4(8.9)$ & $29.9(8.5)$ & $0.387^{\dagger}$ \\
\hline Age groups: & & & & $0.806^{!}$ \\
\hline$<20$ years & $79(9.1)$ & $44(9.7)$ & $35(8.4)$ & \\
\hline$\geq 20 \&<30$ & $165(39.4)$ & $184(40.6)$ & $349(40.0)$ & \\
\hline$\geq 30 \&<40$ & $148(35.3)$ & $148(32.7)$ & $296(33.9)$ & \\
\hline$\geq 40$ & $71(16.9)$ & $77(17.0)$ & $148(17.0)$ & \\
\hline Educational status: & & & & 0.001 \\
\hline Illiterate-Read and write & $65(15.5)$ & $39(8.6)$ & 104(11.9) & \\
\hline$<$ Secondary & $75(17.9)$ & $45(9.9)$ & $120(13.8)$ & \\
\hline Secondary & $156(37.2)$ & $212(46.8)$ & $368(42.2)$ & \\
\hline College or higher & $123(29.4)$ & $157(34.6)$ & $280(32.1)$ & \\
\hline Family income in Saudi Riyals: & & & & 0.002 \\
\hline$<3000$ & $97(23.2)$ & $52(11.4)$ & $149(17.1)$ & \\
\hline$\geq 3000 \&<6000$ & $126(30.1)$ & $130(28.7)$ & $256(29.4)$ & \\
\hline$\geq 6000 \&<10000$ & $112(26.7)$ & $154(34.0)$ & $266(30.5)$ & \\
\hline$\geq 10000$ & $84(20.0)$ & $117(25.8)$ & $201(23.1)$ & \\
\hline Working status: & & & & 0.089 \\
\hline Housewife & $284(67.8)$ & $287(63.4)$ & $571(65.5)$ & \\
\hline Students & $37(8.8)$ & $61(13.5)$ & $98(11.2)$ & \\
\hline In Paid employment & $98(23.4)$ & $105(23.2)$ & $203(23.3)$ & \\
\hline Parity & & & & 0.065 \\
\hline $1-3$ & $184(43.9)$ & $214(47.2)$ & $398(45.6)$ & \\
\hline$>3 \&<8$ & $195(46.5)$ & $174(38.4)$ & $369(42.4)$ & \\
\hline$\geq 8$ & $44(10.5)$ & 61(13.4) & $105(12.0)$ & \\
\hline Duration of pregnancy: & & & & 0.251 \\
\hline $1^{\text {st }}$ trimester & $188(44.9)$ & $211(46.6)$ & $399(45.8)$ & \\
\hline $2^{\text {nd }}$ trimester & $178(42.5)$ & $171(37.7)$ & $349(40.0)$ & \\
\hline $3^{\text {rd }}$ trimester & $53(12.6)$ & $71(15.7)$ & $124(16.2)$ & \\
\hline
\end{tabular}




\begin{tabular}{|c|c|c|c|c|}
\hline \multirow{2}{*}{ Characteristics } & \multirow{2}{*}{ Total $(\mathrm{N}=\mathbf{8 7 2})$} & \multicolumn{2}{|c|}{ Residence: No. (\%) } & \multirow{2}{*}{ P value } \\
\hline & & Rural (N=419) & Urban $(\mathrm{N}=453)$ & \\
\hline Gravidity: & & & & 0.011 \\
\hline Primigravidae & $126(30.1)$ & $105(23.2)$ & $231(26.5)$ & \\
\hline Multigravidae & $239(69.9)$ & $348(76.8)$ & $641(73.5)$ & \\
\hline \multicolumn{5}{|l|}{ Comorbidties *: } \\
\hline Hypertension & $23(5.5)$ & $29(6.4)$ & $52(6.0)$ & \\
\hline Diabetes mellitus & $21(5.0)$ & $27(6.0)$ & $48(5.5)$ & \\
\hline Bronchial asthma & $25(6.0)$ & $29(6.4)$ & $54(6.2)$ & \\
\hline Hemolytic blood diseases (sickle-thalassemia) & $26(6.2)$ & $8(1.8)$ & $34(3.9)$ & \\
\hline More than one comorbidities & $18(4.3)$ & $19(4.2)$ & $37(4.2)$ & \\
\hline Others ${ }^{\ddagger}$ & $28(6.7)$ & $43(9.5)$ & $71(8.1)$ & \\
\hline Previous unfavorable obstetric outcomes: & & & & 0.160 \\
\hline None & $298(71.1)$ & $295(65.1)$ & $593(68.0)$ & \\
\hline One abortion or intra-uterine foetal deaths (IUFD) & $88(21.0)$ & $117(25.8)$ & $205(23.5)$ & \\
\hline$>$ one abortion or IUFD & $33(7.9)$ & $41(9.1)$ & $74(8.5)$ & \\
\hline Investigated for toxoplasmosis * & $74(17.7)$ & $50(11.0)$ & $124(14.2)$ & 0.006 \\
\hline Diagnosed as having toxoplasmosis * & $19(4.5)$ & $18(4.0)$ & $37(4.2)$ & 0.808 \\
\hline Received treatment for toxoplasmosis * & $16(3.8)$ & $15(3.3)$ & $31(3.6)$ & 0.824 \\
\hline
\end{tabular}

$\mathrm{SD}=$ standard deviation, ' Chi-square, "t-test. *Based on reviewing of patients' records. 'Includes nutritional anemia (32 cases), undernutrition (18), epilepsy (2), valvular heart disease ( 2 cases), joints problems (5 cases), and urinary and other infections (12 cases).

\subsection{Toxoplasmosis Risk Behavior}

Table 2 demonstrates toxoplasmosis risk behaviors by residence and duration of pregnancy. Of the included pregnant women $32.0 \%$ mentioned consumption of undercooked/partially cooked meat including Salami, Pastrami, luncheon, sausages, burgers, minced meats and similar foods, of them $17.4 \%$ stated a frequency consumption of at least once /week (median of 2.5 times/week), this was more among rural women and those in their $3^{\text {rd }}$ trimester but without statistical significance. Also, $44.2 \%$ stated eating of unwashed/unpeeled fruits and vegetables, with consumption of at least once/week in $28.2 \%$ significantly more among rural women, and those women in the $2^{\text {nd }}$ and $3^{\text {rd }}$ trimesters of pregnancy. Of the included women $11.3 \%$ mentioned using water wells for drinking significantly higher in rural women. Only $3.9 \%$ of pregnant women owned domestic cats, more in urban and only $16(1.8 \%)$ of the interviewed women mentioned changing the cat's litters. Gardening without gloves was stated by $9.1 \%$ of the women significantly more among rural $(\mathrm{P}=0.001)$ and those $1^{\text {st }}$ and $2^{\text {nd }}$ trimesters compared to those in their $3^{\text {rd }}$ trimester of pregnancy. An additional $6.7 \%$ mentioned using gloves while gardening but without washing their hands. Cleaning of kitchen utensils using hot soapy water was mentioned by $57.0 \%$, more among urban women, least among women in their $1^{\text {st }}$ trimester of pregnancy. Thorough washing of fruits and vegetables before eating was mentioned by $64.6 \%$, more among urban and least among those of $1^{\text {st }}$ trimester but without statistical significance. Washing hands after contact with raw meats/unwashed fruits and vegetables was mentioned by $65.6 \%$ and least among those in their $3^{\text {rd }}$ trimester. 
Table 2. Toxoplasmosis risk behaviors among Saudi pregnant women by residence and duration of pregnancy, Al Hassa, Saudi Arabia

\begin{tabular}{|c|c|c|c|c|c|c|c|c|c|}
\hline \multirow[b]{2}{*}{ Behaviors } & \multicolumn{2}{|c|}{ Total $(\mathrm{N}=872)$} & \multicolumn{2}{|c|}{ Residence: No. (\%) } & \multirow{2}{*}{$\begin{array}{l}P \\
\text { value* }\end{array}$} & \multicolumn{3}{|c|}{ Trimester of pregnancy: No.(\%) } & \multirow{2}{*}{$\begin{array}{l}\mathbf{P} \\
\text { value* }\end{array}$} \\
\hline & No. $(\%)$ & $95 \% \mathrm{CI}$ & $\begin{array}{l}\text { Urban } \\
(\mathrm{N}=453)\end{array}$ & $\begin{array}{l}\begin{array}{l}\text { Rural } \\
(\mathrm{N}=419)\end{array} \\
\end{array}$ & & $\begin{array}{l}1^{\text {st }} \\
(\mathrm{N}=399)\end{array}$ & $\begin{array}{l}2^{\text {nd }} \\
(\mathrm{N}=349)\end{array}$ & $\begin{array}{l}3^{\text {rd }} \\
(\mathrm{N}=124)\end{array}$ & \\
\hline \multicolumn{10}{|l|}{ Eating under/partially cooked meat: } \\
\hline At least once a week & $152(17.4)$ & $15.1-20.1$ & $71(15.7)$ & $81(19.3)$ & 0.154 & $63(15.8)$ & $62(17.8)$ & $27(21.8)$ & 0.301 \\
\hline Less frequent (1-3 times/month). & $127(14.6)$ & $12.4-17.1$ & $78(17.2)$ & $49(11.7)$ & 0.020 & $55(13.8)$ & $49(14.0)$ & $23(18.5)$ & 0.395 \\
\hline \multicolumn{10}{|c|}{ Eating unwashed raw/non peeled fruits and vegetables: } \\
\hline At least once a week & $246(28.2)$ & $25.3-31.3$ & $102(22.5)$ & 144(34.4) & 0.001 & $114(28.6)$ & $101(28.9)$ & $31(25.0)$ & 0.687 \\
\hline Less frequent (1-3 times/month). & $139(15.9)$ & $13.7-18.5$ & $72(15.9)$ & $67(16.0)$ & 0.969 & $74(18.5)$ & $33(9.5)$ & $32(25.8)$ & 0.001 \\
\hline \multicolumn{10}{|l|}{ Drinking water sources: } \\
\hline Water wells (private or public): & $99(11.3)$ & $9.4-13.6$ & $12(2.6)$ & $87(20.8)$ & 0.001 & $47(11.8)$ & $41(11.7)$ & $11(8.9)$ & 0.642 \\
\hline Others (mobile or bottled water): & $773(88.7)$ & $86.4-90.6$ & $441(97.4)$ & $332(79.2)$ & 0.001 & $352(88.2)$ & $278(79.7)$ & 113(91.1) & 0.474 \\
\hline Cat ownership & $34(3.9)$ & $2.8-5.4$ & $21(4.6)$ & $13(3.1)$ & 0.245 & $17(4.3)$ & $16(4.6)$ & $1(0.8)$ & 0.153 \\
\hline Changing cat's litter & $16(1.8)$ & $1.1-3.0$ & $7(1.5)$ & $9(2.1)$ & 0.507 & $9(2.3)$ & $7(2.0)$ & - & 0.813 \\
\hline \multicolumn{10}{|l|}{ Contacting with soil: } \\
\hline Garden at the house & $193(22.1)$ & $19.5-25.0$ & $89(19.6)$ & $104(24.8)$ & 0.065 & $88(22.1)$ & $71(20.3)$ & $34(27.4)$ & 0.264 \\
\hline Gardening without gloves & $79(9.1)$ & $7.3-11.1$ & $25(5.5)$ & $54(12.9)$ & 0.001 & $31(7.8)$ & $30(8.6)$ & $8(6.5)$ & 0.741 \\
\hline $\begin{array}{l}\text { Gardening with gloves but without } \\
\text { hand washing }\end{array}$ & $58(6.7)$ & $5.2-8.5$ & $25(5.5)$ & $33(7.9)$ & 0.162 & $28(7.3)$ & $23(6.6)$ & $6(4.8)$ & 0.691 \\
\hline $\begin{array}{l}\text { Cleaning kitchen utensils (knives/ } \\
\text { cutting boards/ utensils/ counters): }\end{array}$ & $497(57.0)$ & $53.7-60.2$ & $268(59.2)$ & $229(54.7)$ & 0.179 & 198(49.6) & $237(67.9)$ & $62(50.0)$ & 0.001 \\
\hline $\begin{array}{l}\text { Thorough washing of fruits and } \\
\text { vegetables before eating: }\end{array}$ & $563(64.6)$ & $61.3-67.7$ & $301(66.4)$ & $262(62.5)$ & 0.227 & $241(60.4)$ & $239(68.5)$ & $83(66.9)$ & 0.058 \\
\hline $\begin{array}{l}\text { Washing hands after contact with raw } \\
\text { meats/ unwashed fruits and vegetables: }\end{array}$ & $574(65.8)$ & $62.6-68.9$ & $296(65.3)$ & $278(66.3)$ & 0.754 & $262(65.7)$ & $241(69.1)$ & $71(57.3)$ & 0.058 \\
\hline
\end{tabular}

The term cats' illness (disease) was used to indicate toxoplasmosis.

$\mathrm{CI}=$ confidence intervals $*$ Chi Square test.

\subsection{Correlates of Toxoplasmosis Preventive Behavior}

Saudi pregnant women fulfilled the recommended behaviors to prevent congenital toxoplasmosis constituted $26.8 \%$ $(\mathrm{n}=234)$, significantly more among urban compared to rural women $(30.0 \%$ vs. $23.4 \%$ rural $)$ but not associated with the duration of pregnancy $\left(97 / 399,24.3 \%\right.$ among those in the $1^{\text {st }}$ trimester, $101 / 349,28.9 \%$ in the $2^{\text {nd }}$ and $36 / 124,29.0 \%$ in the $\left.3^{\text {rd }}, \mathrm{P}=0.304\right)$. Of the included women, $426(48.9 \%)$ had at least one risk behavior, while those with $\geq$ two risk behaviors constituted $24.3 \%$ ( $\mathrm{n}=212)$, more among rural women $(28.4 \%$ compared to $20.6 \%$ urban, $\mathrm{P}=0.010)$. The preventive behavior is largely stemmed from not contacting with cat and cat's litter $(98.2 \%)$, not contacting with soil (90.9\%), safe water supply $(88.7 \%)$, not eating undercooked and raw meat $(82.6 \%)$, and no consumption of unwashed/unpeeled fruits and vegetables (71.8\%).

Table 3 displays univariate and multivariate regression model of the possible correlates for toxoplasmosis preventive behavior. Pregnant urban women aged 20 to $<30$ years (Odds ratio $\mathrm{OR}=2.37$, confidence intervals $\mathrm{CI}=1.72-3.28)$, with $\geq$ secondary education $(\mathrm{OR}=1.64, \mathrm{CI}=1.12-2.41)$ and with history of two or more abortion and/or IUFDs ( $\mathrm{OR}=5.33, \mathrm{CI}=3.16-9.03)$ were more likely to follow preventive behavior as revealed by univariate analysis. Multivariate logistic regression model demonstrates that pregnant women with $\geq$ secondary education $(\mathrm{OR}=1.59)$, aged 20 to $<30$ years $(\mathrm{OR}=2.11)$ and those with two or more abortions and/or IUFDs $(\mathrm{OR}=4.7)$ were positive predictors for adopting toxoplasmosis preventive behavior. 
Table 3. Possible socio-demographic and obstetric predictors for toxoplasmosis preventive among the included Saudi pregnant women, Al Hassa, Saudi Arabia

\begin{tabular}{|c|c|c|c|c|}
\hline \multirow{2}{*}{ Variables } & \multicolumn{2}{|c|}{ Preventive behavior!: No. (\%) } & \multirow{2}{*}{$\begin{array}{l}\text { Univaraite analysis } \\
\text { Odds ratio (95\% CI) }\end{array}$} & \multirow{2}{*}{$\begin{array}{l}\text { Multivariate logistic regression } \\
\text { Odds ratio }(95 \% \mathrm{CI})\end{array}$} \\
\hline & Yes $(\mathbf{N}=\mathbf{2 3 4})$ & No $(\mathrm{N}=638)$ & & \\
\hline \multicolumn{5}{|l|}{ Age groups: } \\
\hline$<20$ years & $30(12.8)$ & $49(7.7)$ & Reference & Reference \\
\hline$\geq 20 \&<30$ & $137(58.5)$ & $212(33.2)$ & $2.37(1.72-3.28)^{* *}$ & $2.11(1.63-2.74)^{* *}$ \\
\hline$\geq 30$ & $66(28.2)$ & $306(48.0)$ & $0.34(0.24-0.58)^{* *}$ & $0.33(0.21-0.51)^{* *}$ \\
\hline \multicolumn{5}{|l|}{ Residence: } \\
\hline Rural & 98(41.9) & $321(50.3)$ & Reference & Reference \\
\hline Urban & $136(58.1)$ & $317(49.7)$ & $1.41(1.03-1.92)^{*}$ & $1.37(0.96-1.90)$ \\
\hline \multicolumn{5}{|l|}{ Educational status: } \\
\hline$<$ Secondary & $45(19.2)$ & $179(28.1)$ & Reference & Reference \\
\hline Secondary or higher & $189(80.8)$ & $459(71.9)$ & $1.64(1.12-2.41)^{*}$ & $1.59(1.08-2.35)^{*}$ \\
\hline \multicolumn{5}{|l|}{ Family income in Saudi Riyals } \\
\hline$<3000$ & $31(13.2)$ & $118(18.5)$ & Reference & -- \\
\hline$\geq 3000 \&<6000$ & $66(28.2)$ & $190(29.8)$ & $0.93(0.66-1.31)$ & -- \\
\hline$\geq 6000$ & $137(58.5)$ & $330(51.7)$ & $1.32(0.96-1.89)$ & -- \\
\hline \multicolumn{5}{|l|}{ Working status: } \\
\hline Housewife/Students & $176(75.2)$ & 493(77.3) & Reference & -- \\
\hline In Paid employment & $58(24.8)$ & $145(22.7)$ & $1.12(0.78-1.61)$ & -- \\
\hline \multicolumn{5}{|l|}{ Parity } \\
\hline $1-3$ & $111(47.4)$ & $287(45.0)$ & Reference & -- \\
\hline$\geq 4 \&<8$ & 92(39.4) & $277(43.4)$ & $0.84(0.61-1.16)$ & -- \\
\hline$\geq 8$ & $31(13.2)$ & $74(11.6)$ & $1.16(0.72-1.86)$ & -- \\
\hline \multicolumn{5}{|l|}{ Previous unfavorable obstetric outcomes: } \\
\hline None & $172(73.5)$ & $421(66.0)$ & Reference & Reference \\
\hline One abortion or IUFD & $16(6.8)$ & $189(29.6)$ & $0.17(0.10-0.31)^{* *}$ & $0.14(0.10-0.30)^{* *}$ \\
\hline$>$ One abortion or IUFD & $46(19.7)$ & $28(4.4)$ & $5.33(3.16-9.03)^{* *}$ & $4.71(3.09-7.19)^{* *}$ \\
\hline Previously investigated for toxoplasmosis: & $28(12.0)$ & $96(15.0)$ & $0.77(0.48-1.23)$ & -- \\
\hline
\end{tabular}

$\mathrm{CI}=$ Confidence intervals $* \mathrm{P}<0.05,{ }^{*} \mathrm{P}<0.001$. ' Fulfilling all criteria recommended by the Centers for Disease Control and Prevention to prevent congenital toxoplasmosis.

\subsection{Toxoplasmosis-Related Knowledge}

Table 4 displays the correct responses regarding toxoplasmosis-related knowledge stated by pregnant women and distributed by their residence and duration of pregnancy. The majority of the pregnant women failed to identify the role of undercooked /partially cooked meat consumption, contaminated water, eating unwashed fruits and vegetables and contacting with soil in transmitting infection. Only $13.4 \%$ correctly stated that toxoplasmosis can produce serious complications in the unborn child, $10.2 \%$ recognized that toxoplasmosis can pass to the fetus if the pregnant women is newly infected. The domain of knowledge related to toxoplasmosis prevention showed higher correct responses compared to infection transmission and congenital toxoplasmosis. The total knowledge score ranged from 0 to 16 (out of 20 points), median of 5.0, IQR=7.0, mean (SD) 4.9 \pm 2.7 , higher among urban (mean $5.1 \pm 2.8$ ) compared to rural (4.6 \pm 1.7 ) (Mann Whitney, $\mathrm{P}=0.006$ ). The knowledge score was significantly correlated with the duration of pregnancy, least among those in the $1^{\text {st }}$ trimester compared to those in the $2^{\text {nd }}$ and $3^{\text {rd }}$ trimester (Kruskal Wallis, $\mathrm{P}=0.015$ ). 
Table 4. Toxoplasmosis related knowledge among pregnant women by residence and duration of pregnancy, $\mathrm{Al}$ Hassa, Saudi Arabia

\begin{tabular}{|c|c|c|c|c|c|c|c|c|}
\hline \multirow[b]{2}{*}{ Items } & \multicolumn{3}{|c|}{ Correct responses: No. (\%) } & \multirow{2}{*}{$\begin{array}{l}P \\
\text { value* }^{*}\end{array}$} & \multicolumn{3}{|c|}{ Trimester of pregnancy: No. (\%) } & \multirow{2}{*}{$\begin{array}{l}\text { P } \\
\text { value* }\end{array}$} \\
\hline & $\begin{array}{l}\text { Total } \\
(\mathrm{N}=872)\end{array}$ & $\begin{array}{l}\text { Urban } \\
(N=453)\end{array}$ & $\begin{array}{l}\text { Rural } \\
(\mathrm{N}=419)\end{array}$ & & $1^{\text {st }}(\mathrm{N}=399)$ & $2^{\text {nd }}(\mathrm{N}=\mathbf{3 4 9})$ & $3^{\text {rd }}(\mathrm{N}=124)$ & \\
\hline Ever heard/read about toxoplasmosis: & $367(42.1)$ & $178(39.3)$ & $185(44.2)$ & 0.165 & $161(40.3)$ & $149(42.7)$ & $57(46.0)$ & 0.518 \\
\hline \multicolumn{9}{|l|}{ Infection transmission: } \\
\hline Toxoplasmosis is caused by___ (options): Infection & $148(17.0)$ & $88(19.4)$ & $60(14.3)$ & 0.055 & $61(15.2)$ & $60(17.2)$ & $27(21.8)$ & 0.241 \\
\hline Dealing with cats increase the risk of infection: True & $341(39.1)$ & $182(40.2)$ & $159(37.9)$ & 0.545 & $159(39.8)$ & $146(40.1)$ & $42(33.9)$ & 0.297 \\
\hline Toxoplasmosis agent is present in cats' feaces: True & $304(34.9)$ & 166(36.6) & $138(32.9)$ & 0.281 & $132(33.1)$ & $123(35.2)$ & $49(39.5)$ & 0.414 \\
\hline Toxoplasmosis agent can be found in undercooked meat: True & $133(15.3)$ & $70(15.5)$ & $63(15.0)$ & 0.938 & $60(15.0)$ & $53(15.2)$ & $20(16.1)$ & 0.956 \\
\hline $\begin{array}{l}\text { Eating undercooked meat increases the risk of } \\
\text { toxoplasmosis: True }\end{array}$ & $129(14.8)$ & $61(13.5)$ & $46(11.0)$ & 0.310 & $53(13.3)$ & $53(15.2)$ & $23(18.5)$ & 0.341 \\
\hline $\begin{array}{l}\text { Drinking water contaminated with toxoplasmosis } \\
\text { increases the risk: True }\end{array}$ & $83(9.5)$ & $37(8.2)$ & $46(11.0)$ & 0.194 & $31(7.8)$ & $33(9.5)$ & $19(15.3)$ & 0.043 \\
\hline $\begin{array}{l}\text { Eating unwashed fruits and vegetables increases risk of } \\
\text { toxoplasmosis: True }\end{array}$ & $66(7.6)$ & $39(8.6)$ & $27(6.4)$ & 0.280 & $28(7.0)$ & $26(7.4)$ & $13(10.5)$ & 0.438 \\
\hline $\begin{array}{l}\text { Gardening without gloves may increases risk of } \\
\text { toxoplasmosis: True }\end{array}$ & 101(11.6) & $59(13.0)$ & $42(10.0)$ & 0.201 & $41(10.3)$ & $47(13.5)$ & $13(10.5)$ & 0.363 \\
\hline \multicolumn{9}{|l|}{ Congenital toxoplasmosis: } \\
\hline $\begin{array}{l}\text { Toxoplasmosis can cause severe symptoms to the } \\
\text { pregnant: False }\end{array}$ & $147(16.9)$ & $92(20.3)$ & $55(13.1)$ & 0.006 & $54(13.5)$ & $67(19.2)$ & $26(21.0)$ & 0.049 \\
\hline $\begin{array}{l}\text { Toxoplasmosis can produce serious complications in } \\
\text { unborn /newborn child: True }\end{array}$ & $117(13.4)$ & $71(15.7)$ & $46(11.0)$ & 0.053 & $47(11.8)$ & $49(14.0)$ & $21(16.9)$ & 0.307 \\
\hline $\begin{array}{l}\text { Toxoplasmosis can pass to the fetus if the pregnant is } \\
\text { newly infected. True }\end{array}$ & $89(10.2)$ & $44(9.7)$ & $45(10.7)$ & 0.697 & $32(8.0)$ & $39(11.2)$ & $18(14.5)$ & 0.084 \\
\hline $\begin{array}{l}\text { Chronically infected pregnant women rarely pass } \\
\text { toxoplasmosis to her fetus. True }\end{array}$ & $83(9.5)$ & $51(11.2)$ & $32(7.6)$ & 0.088 & $28(7.0)$ & $38(10.9)$ & $17(13.7)$ & 0.045 \\
\hline $\begin{array}{l}\text { A baby with Toxoplasmosis may have no signs of illness at } \\
\text { birth, but develop latter. True }\end{array}$ & 121(13.9) & $68(15.0)$ & $53(12.6)$ & 0.362 & $45(11.3)$ & $49(14.0)$ & $27(21.8)$ & 0.012 \\
\hline A baby with toxoplasmosis can have visual problems: True & 102(11.7) & $50(11.0)$ & $52(12.4)$ & 0.599 & $33(8.3)$ & $41(11.7)$ & $28(22.6)$ & 0.008 \\
\hline A baby with toxoplasmosis can have mental problems: True & $119(13.6)$ & $60(13.2)$ & $59(14.1)$ & 0.794 & $43(10.8)$ & $52(14.9)$ & 24(19.4) & 0.035 \\
\hline \multicolumn{9}{|l|}{ Toxoplasmosis prevention: } \\
\hline $\begin{array}{l}\text { Toxoplasmosis can be prevented by avoid dealing with } \\
\text { cat's feaces: True }\end{array}$ & $289(33.1)$ & $186(41.1)$ & 103(24.6) & 0.111 & $103(25.8)$ & $133(38.1)$ & $53(42.7)$ & 0.001 \\
\hline $\begin{array}{l}\text { Thorough cooking of meat until no pink is seen can } \\
\text { prevent toxoplasmosis: True }\end{array}$ & $231(26.5)$ & $133(29.4)$ & $98(23.4)$ & 0.054 & $101(25.3)$ & $96(27.5)$ & $34(27.4)$ & 0.769 \\
\hline $\begin{array}{l}\text { Avoid eating of raw/undercooked meat can prevent } \\
\text { toxoplasmosis: True }\end{array}$ & $181(20.8)$ & $94(20.8)$ & $87(20.8)$ & 0.937 & $79(19.8)$ & $71(20.3)$ & $31(25.0)$ & 0.445 \\
\hline $\begin{array}{l}\text { Thorough washing and /or peeling of fruits and vegetables } \\
\text { before eating can prevent toxoplasmosis: True }\end{array}$ & $277(31.7)$ & $159(35.1)$ & $118(28.2)$ & 0.033 & $123(30.8)$ & $106(30.4)$ & $48(38.7)$ & 0.198 \\
\hline $\begin{array}{l}\text { Cleaning of knives, cutting boards and utensils after each } \\
\text { use can prevent toxoplasmosis. True }\end{array}$ & $267(30.6)$ & $148(32.7)$ & $119(28.4)$ & 0.195 & $142(35.6)$ & $102(29.2)$ & $41(33.1)$ & 0.179 \\
\hline Knowledge score: median $($ mean \pm SD) & $5.0(4.9 \pm 2.7)$ & $5.0(5.1 \pm 2.8)$ & $4.0(4.6 \pm 1.7)$ & $0.006^{!}$ & $4.0(4.3 \pm 1.4)$ & $5.0(4.8 \pm 2.1)$ & $5.25(4.9 \pm 2.8)$ & $0.015^{\dagger}$ \\
\hline Interquartile range $\left(25^{\text {th }}-75^{\text {th }}\right.$ percentiles $)$ & $1.0-8.0$ & $1.0-8.0$ & $0.0-7.0$ & 0.000 & $0.0-7.0$ & $1.0-8.0$ & $1.0-8.0$ & 0.015 \\
\hline
\end{tabular}

* Chi-square test. 'Mann Whitney, ${ }^{\dagger}$ Kruskal Wallis test.

Table 5 demonstrates the univaraite analysis of socio-demographics and obstetric factors against the knowledge scores applying cut of $\geq 8$ points for being knowledgeable to toxoplasmosis. Of the included pregnant women, 219 $(25.1 \%)$ scored 8 or more points for knowledge. Univaraite analysis showed that urban woman, within the age range of $30-<40$ years, with $\geq$ secondary education, having previous unfavorable pregnancy outcomes, and being previously investigated for toxoplasmosis were more knowledgeable. Those in the $1^{\text {st }}$ trimester of pregnancy were 
the least likely to be knowledgeable ( $\mathrm{OR}=0.39, \mathrm{CI}=0.28-0.55, \mathrm{P}=0.001)$. Family income, parity, working status and preventive behavior were not significantly correlated with the knowledge status. Also table 5 displays the results of multivariate logistic regression model showed that women aged 30 to $<40$ years $(\mathrm{OR}=1.53$, $\mathrm{CI}=1.09-2.15)$, with $\geq$ secondary education $(\mathrm{OR}=1.96, \mathrm{CI}=1.54-2.49)$, previous history of unfavorable pregnancy outcomes $(\mathrm{OR}=1.88, \mathrm{CI}=1.13-2.99)$ and previously investigated for toxoplasmosis $(\mathrm{OR}=2.08, \mathrm{CI}=1.61-2.67)$ were significantly more knowledgeable towards toxoplasmosis.

Table 5. Univariate and multivariate logistic regression analysis of the possible socio-demographic and obstetric history correlates of toxoplasmosis-related knowledge among the included pregnant women, Al Hassa, Saudi Arabia

\begin{tabular}{|c|c|c|c|c|c|c|}
\hline \multirow[b]{2}{*}{ Independent variables } & \multicolumn{2}{|c|}{ Knowledge level: No. (\%) } & \multirow{2}{*}{$\begin{array}{l}\text { Univariate analysis } \\
\text { (Odds ratio and 95\% } \\
\text { CI) }\end{array}$} & \multirow[b]{2}{*}{ P value } & \multirow{2}{*}{$\begin{array}{l}\text { Multivariate } \\
\text { regression model } \\
\text { Odds }(95 \% \mathrm{CI})\end{array}$} & \multirow[b]{2}{*}{ Pvalue } \\
\hline & $\begin{array}{l}\text { Low }(<8) \\
(N=653)\end{array}$ & $\begin{array}{l}\text { High }(\geq 8) \\
(\mathrm{N}=219)\end{array}$ & & & & \\
\hline \multicolumn{7}{|l|}{ Residence: } \\
\hline Rural & $336(51.5)$ & $83(37.9)$ & Reference & & Reference & \\
\hline Urban & $317(48.5)$ & $136(62.1)$ & $1.74(1.25-2.41)$ & 0.001 & $1.55(0.89-2.36)$ & 0.115 \\
\hline \multicolumn{7}{|l|}{ Age groups: } \\
\hline$<20$ & $68(10.4)$ & $11(5.0)$ & Reference & & Reference & \\
\hline$\geq 20 \&<30$ & $265(40.6)$ & $84(38.4)$ & $0.91(0.66-1.26)$ & 0.090 & $0.87(0.61-1.24)$ & 0.360 \\
\hline$\geq 30 \&<40$ & $204(31.2)$ & $92(42.0)$ & $1.59(1.15-2.21)$ & 0.003 & $1.53(1.09-2.15)$ & 0.034 \\
\hline$\geq 40$ & $116(17.8)$ & $32(14.6)$ & $0.79(0.51-1.24)$ & 0.282 & $0.73(0.48-1.12)$ & 0.287 \\
\hline \multicolumn{7}{|l|}{ Educational status: } \\
\hline$<$ secondary & $194(29.7)$ & $30(13.7)$ & Reference & & Reference & 0.006 \\
\hline Secondary or higher & $459(70.3)$ & $189(86.3)$ & $2.66(1.72-4.15)$ & 0.001 & $1.96(1.54-2.49)$ & \\
\hline \multicolumn{7}{|l|}{ Family income: } \\
\hline$<6000 \mathrm{SR}$ & $299(45.8)$ & $106(48.4)$ & Reference & & & \\
\hline$\geq 6000 \mathrm{SR}$ & $354(54.2)$ & $113(51.6)$ & $0.91(0.66-1.25)$ & 0.538 & -- & \\
\hline \multicolumn{7}{|l|}{ Working: } \\
\hline Housewives/students & $508(77.8)$ & $161(73.5)$ & Reference & & & \\
\hline Working & $145(22.2)$ & $58(26.5)$ & $1.26(0.91-1.72)$ & 0.190 & -- & \\
\hline \multicolumn{7}{|l|}{ Parity: } \\
\hline $1-3$ & $289(44.3)$ & $109(49.8)$ & Reference & & & \\
\hline 4 or more & $364(55.7)$ & $110(50.2)$ & $0.80(0.58-1.10)$ & 0.156 & -- & \\
\hline \multicolumn{7}{|l|}{ Trimester of pregnancy: } \\
\hline $1 \mathrm{st}$ & $235(51.3)$ & $64(29.2)$ & Reference & & Reference & \\
\hline $2 \mathrm{nd}$ & $232(35.5)$ & $117(53.4)$ & $1.58(1.14-2.19)$ & 0.002 & $1.43(0.98-2.09)$ & 0.091 \\
\hline $3 \mathrm{rd}$ & $86(13.2)$ & $38(17.4)$ & $1.14(0.73-1.70)$ & 0.539 & $1.07(0.69-1.66)$ & 0.601 \\
\hline \multicolumn{7}{|c|}{ Previous unfavorable pregnancy outcomes: } \\
\hline None & $480(73.5)$ & $113(51.6)$ & Reference & & Reference & \\
\hline One or more & $173(26.5)$ & $106(48.4)$ & $2.60(1.87-3.62)$ & 0.001 & $1.88(1.13-2.99)$ & 0.016 \\
\hline \multicolumn{7}{|c|}{ Previously investigated for toxoplasmosis during pregnancy: } \\
\hline None & $582(89.1)$ & $166(75.8)$ & Reference & & Reference & \\
\hline Yes & 71(10.9) & $53(24.2)$ & 2.62(1.73-3.96) & 0.001 & $2.08(1.61-2.67)$ & 0.009 \\
\hline \multicolumn{7}{|l|}{ Preventive behavior: } \\
\hline No & $480(73.5)$ & $158(72.1)$ & Reference & & & \\
\hline Yes & $173(26.5)$ & $61(27.9)$ & $1.07(0.75-1.53)$ & 0.694 & -- & \\
\hline
\end{tabular}

$\mathrm{CI}=$ Confidence intervals. Percent predicted for the multivariate regression model $=75.8$, Homser and Lemeshow Chi square $=4.539, \mathrm{P}=0.602$

Figure 1 displays the cited sources of toxoplasmosis-related knowledge cited by the included Saudi pregnant women, $521(59.7 \%)$ stated that they never heard/read about toxoplasmosis, while $351(40.3 \%)$ had mentioned that they have read/hear about the condition and cited their sources of toxoplasmosis-related knowledge. These sources included Television programs 55/351 (15.7\%), Internet by 88/351 (25.1), close friends/family relatives and 
workmate $68 / 351$ (19.4\%), health related booklets, brochures and papers 58/351 (16.5\%), health care providers by $62 / 351(17.7 \%)$ and $20 / 351(5.6 \%)$ had cited more than one source.

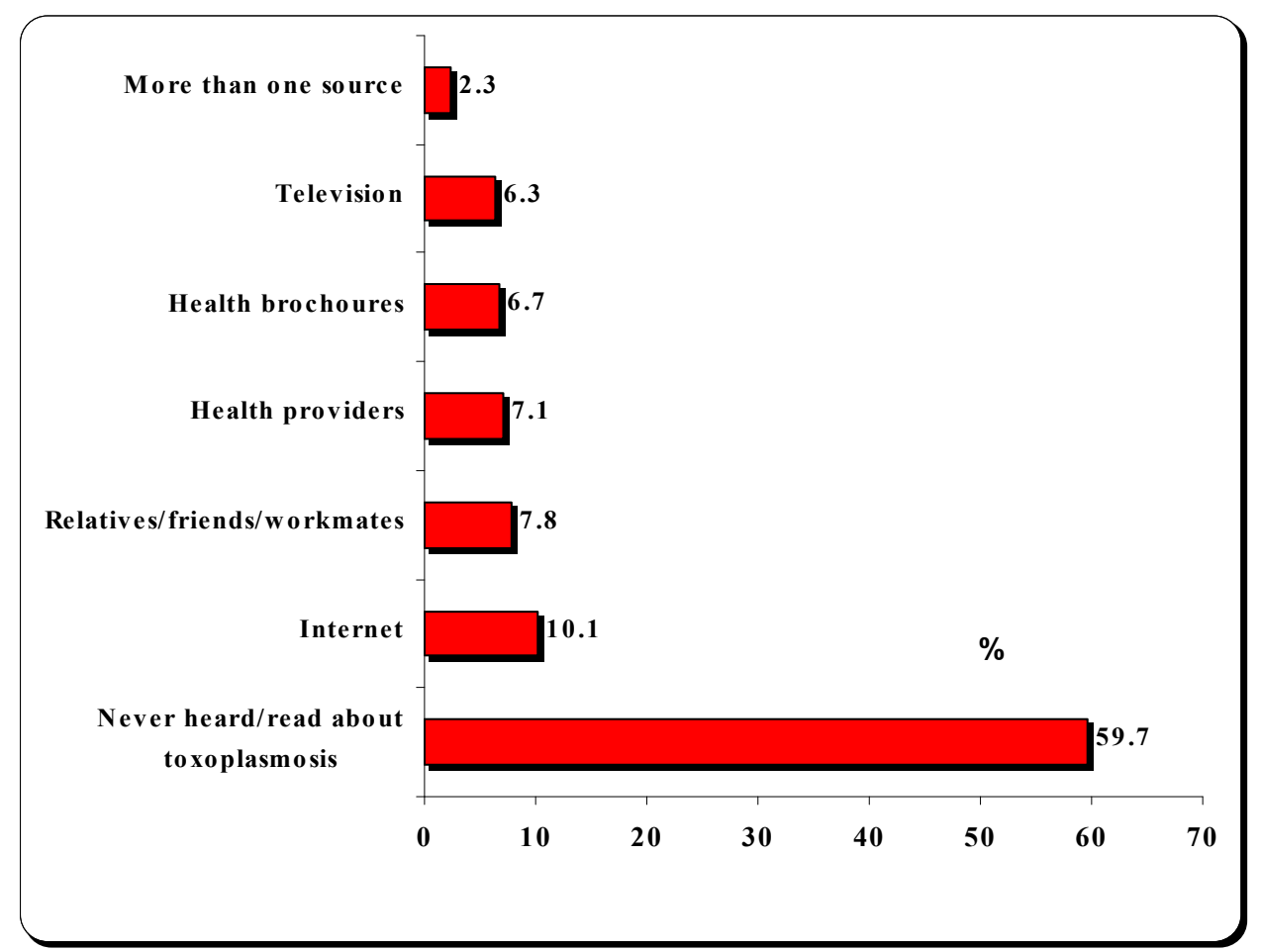

Figure 1. Sources of information regarding toxoplasmosis cited by the included Saudi pregnant women, Al Hassa, Saudi Arabia

\section{Discussion}

This study shows that toxoplasmosis risk behavior among the included Saudi pregnant women is largely stemmed form hygienic habits in the form of non-cleaning of kitchen utensils, non washing of hands after dealing with raw meats and vegetables, and non thorough washing of fruits and vegetables. Studies from Turkey (Ertug et al., 2005) and Palestine (Nijem \& Al-Amleh, 2009) reported a positive association between raw meats consumption with toxoplasmosis infection. Al Qahtani and Hassan (2012) explained the urban-rural difference in toxoplasmosis seroprevalence by the differential distribution of risk factors in Nigran (Southern Saudi Arabia) including frequent consumption of undercooked meat, unpasteurized milk, unfiltered municipal water, raw or non-washed vegetables or fruit and soil contact. Moreover, higher number of cats in rural areas especially inside houses may be responsible for that higher difference in rural localities (Al-Harthi et al., 2006). Understanding the preventive behavior of pregnant women may aid in counseling which of paramount importance in lowering the fetal risk. In this study the proportion of pregnant women followed a preventive behavior is higher compared to those reported from Brazil 16.3\% of pregnant women demonstrated preventive behavior (Costa et al., 2012). In this study pregnant women aged 20 to $<30$ years and those with repeated abortions or intrauterine fetal deaths were more likely to follow preventive behavior. These findings are consistent with those reported from one study in other Brazil (Costa et al., 2012) where no significant associations were found between preventive behavior with sociodemographics, gestational age and IgG positivity. Other study had linked preventive behavior for toxoplasmosis with eating and hygienic habits (Carneil et al., 2006). Belarmino et al. (2009) have reported that preventive behavior for toxoplasmosis among pregnant women was chiefly stemmed from the changes in the eating habits that occur during pregnancy, while others postulated that non-preventive behavior among pregnant women resulted from the lack of information (Costa et al., 2012; Belarmino et al., 2009). Low family income and little formal schooling among the pregnant women can contribute to increase the risk for infection (Costa et al., 2012). Our results showed that $\geq$ secondary education was significantly associated with higher preventive behavior, while family income did not. Toxoplasmosis was considered by many gynecologists in the developing countries as the primary cause of bad obstetric outcome; this is viewed by the public and had created a type of panic reaction 
among population and especially women (Razzak et al., 2005). Women with bad obstetric history attributed abortion and IUFDs to toxoplasmosis and hence seek care for investigating and even treatment of toxoplasmosis without physician referral (Giofangrandi et al., 1994). The previous notion may partially explain the effect of bad obstetric history in the form of repeated abortions and/or IUFDs on both preventive behavior and the state of knowledge as reveled from this study.

In this study pregnant women cited that contacting with cat and changing cat's litter to be the most likely method for transmission while most of them failed to identify the roles of eating undercooked meat, soil contacting and consumption of unwashed fruits and vegetables. The results of the current study are close to those reported from Brazil where $65 \%$ of included pregnant women did not know about the disease and most of them associated toxoplasmosis with having cats as pets and less than one third of the participants associated the disease with handling and consumption of undercooked meats and raw vegetables (Varella et al., 2009). Also, Jones et al in their survey showed that $60 \%$ of pregnant women associated transmission of toxoplasmosis to cats and only $30 \%$ were aware of the risk of acquiring the infection from raw or undercooked meat (Jones et al., 2001). Adequate knowledge of risk factors for toxoplasmosis infection supports the preventive measures against severe complications resulted from congenital infection and only with this knowledge can pregnant women lower the risk for fetal infection (Kravtz et al., 2005).

In this study the highest level of knowledge was about the association between cats and toxoplasmosis with low level of knowledge about the role of other modes of transmission. Similar results were reported among U.S pregnant women (Jones et al., 2001) and even among obstetricians and gynecologists (Jones et al., 2003). Also this study demonstrated that many women have shown fair knowledge regarding the preventive practices which is consistent with a U.S study where the majority of the included women picked up correct preventive practices to avoid infection. This study as well other confirmed that disease specific knowledge was not necessarily associated with preventive behavior during pregnancy, regarding toxoplasmosis and conversely, a lack of knowledge was not always associated with engaging in risk behavior. Health education for infectious diseases especially those with grave complications are to be considered early in the antenatal period (Kravtz et al., 2005; Jones et al., 2001; Jones et al., 2003). A Canadian study has shown that even brief education of pregnant women helps to improve toxoplasmosis preventive behaviors (Carter et al., 1989). Health education was associated with reduction in toxoplasmosis seroconversion (Foulon et al., 1994), hence the importance of providing health education as a tool in prevention of congenital toxoplasmosis. Education about meat-cat-soil-related hygiene should be provided to women of childbearing age and to pregnant women at their first prenatal visit. It is important that the educational materials be complete and accurate and that they be made available in a culturally and linguistic appropriate format (Foulon et al., 1994; Pawlowski et al., 2001).

\section{Study Limitations}

To the authors' knowledge this is the first primary care-based study that explores toxoplasmosis-related preventive behavior and knowledge among pregnant women in Saudi Arabia. Nevertheless, the results of the current study should be cautiously interpreted in the lights of the following limitations: First, the study population was not representative of all pregnant women in Saudi Arabia. Second, possible inherent limitations of the study design with the potential recall bias and over/under reporting of the included risk and preventive behavior. Third, the behavioral questions may have contributed to social desirability bias, which may have affected the frequency of the reported risk behavior among the included sample. Moreover, the questionnaire design especially with regard to knowledge about toxoplasmosis was largely based on true/false and do not know format options with high probability of guessing which we did not control, validation of the such instruments need further studies. Fourth, causal relationship between risk behavior, seroconversion and/or pregnancy outcome were not carried out which imply more cautious interpretation of the results. Finally, the effects of adopting risk and preventive behavior were not assessed due to nature of the study design.

\section{Conclusion}

Pregnant women in Al Hasas, Saudi Arabia, are substantially vulnerable to toxoplasmosis infection as they are lacking the necessary preventive behavior. A sizable portion have no sufficient knowledge for primary prevention of congenital toxoplasmosis, health education at primary care is necessary to avert the potential toxoplasmosis related complications especially in the neonates.

\section{References}

Abdalla, K. F., el Fakahany, A. F., Arafa, M. A., Salama, M. M., \& Morsy, T. A. (1995). Congenital toxoplasmosis among premature infants with different clinical pictures in Saudi Arabia. Eur J Epidemiol, 24(3), 643-8. 
Al-Harthi, S. A., Jamjoom, M. B., \& Ghazi, H. O. (2006). Seroprevalence of Toxoplasma gondii among pregnant women in Makkah, Saudi Arabia. Umm Al-Qura University J Sci Med, 18(2), 217-27.

Al-Mohammad, H. I., Amin, T. T., Balaha, M. H., \& Al-Moghannum, M. S. (2010). Toxoplasmosis among the pregnant women attending a Saudi maternity hospital: sero-prevalence and possible risk factors. Ann. Trop. Med. Parasitol, 104(6), 493-504. http://dx.doi.org/10.1179/136485910X12786389891443

Alqahtani, J., \& Hassan, M. M. (2012). Incidence of toxoplasmosis gondii in Najran region, KSA. J Egypt Soc Parasitol, 42(2), 253-260.

Baril, L., Ancelle, T., Goulet, V., Thulliez, P., Tirard-Fleury, V., \& Carme, B. (1999). Risk factors for Toxoplasma infection in pregnancy: a case-control study in France. Scand $J$ Infect Dis, 31, 305-309. http://dx.doi.org/10.1080/00365549950163626

Belarmino, G. O., Moura, E. R. F., Nancy Oliveira, N. C., \& Freitas, G. L. (2009). Nutritional risks among pregnant teenagers. Acta Paul Enferm, 22, 169-175.

Bobic, G., Jenum, P. A., \& Stray-Pedersen, B. (1996). Risk factors for Toxoplasma gondii infection in pregnancy. Results of a prospective case-control study in Norway. Am J Epidemiol, 144, 405-412. http://dx.doi.org/10.1093/oxfordjournals.aje.a008942

Bobic, B., Jevremovic, I., \& Marinkovic, J. (1998). Risk factors for Toxoplasma infection in a reproductive age female population in the area of Belgrade, Yugoslavia. Eur $J$ Epidemiol, 14, 605-610. http://dx.doi.org/10.1023/A:1007461225944

Carniel, E. F., Zanolli, M. L., Almeida, C. A. A., \& Morcillo, A. M. (2006). Characteristics of adolescent mothers and their newborns and risk factors associated to pregnancy in Campinas, SP, Brazil. Rev Bras Saúde Mater Infant, 6, 419-426.

Carter, A. O., Gelmon, S. B., Wells, G. A., \& Toepell, A. P. (1989). The effectiveness of a prenatal education programme for the prevention of congenital toxoplasmosis. Epidemiol Infect, 103, 539-45. http://dx.doi.org/10.1017/S0950268800030934

Cook, A. J., Gilbert, R. E., Buffolano, W., Zufferey, J., Petersen, E., Jenum, P. A., ... Dunn, D. T. (2000). Sources of Toxoplasma infection in pregnant women: European multicentre case-control study. BMJ, 321, 142-147. http://dx.doi.org/10.1136/bmj.321.7254.142

Costa, F. F., Gondim, A. P., de Lima, M. B., Braga, J. U., Vieira, L. J., \& Araújo, M. A. (2012). Preventive behavior for toxoplasmosis in pregnant adolescents in the state of Ceara, Brazil. BMC Public Health, 12, 73. http://dx.doi.org/10.1186/1471-2458-12-73

Dar, F. K., Alkarmi, T., Uduman, S., Abdulrazzaq, Y., Grundsell, H., \& Hughes, P. (1997). Gestational and neonatal toxoplasmosis: Regional seroprevalence in the United Arab Emirates. Eur J Epidemiol, 13(5), 567-571. http://dx.doi.org/10.1023/A:1007392703037

Dubey, J. P. (2010). Toxoplasmosis of Animals and Humans. Beltseville: CRC Press.

Ertug, S., Okyay, P., Turkmen, M., \& Yuksel, H. (2005). Seroprevalence and risk factors for Toxoplasma infection among pregnant women in Aydin province, Turkey. BMC Public Health, 5, 66. http://dx.doi.org/10.1186/1471-2458-5-66

Foulon, W., Naessens, A., \& Derde, M. P. (1994). Evaluation of the possibilities for preventing congenital toxoplasmosis. Am J Perinatol, 11, 57-62. http://dx.doi.org/10.1055/s-2007-994537

Giofangrandi, Y. et al. (1994). Fetal infection. In DK James et al. (Eds.), High risk pregnancy: management options (pp. 841-70). London: WB Sounders.

Jones, J. L., Dietz, V. J., Power, M., Lopez, A., Wilson, M., Navin, T. R., ... Schulkin, J. (2001). Survey of obstetricians gynecologists in the United States about toxoplasmosis. Infect Dis Obstet Gynecol, 9, 23-31. http://dx.doi.org/10.1155/S1064744901000059

Jones, J. L., Ogunmodede, F., Scheftel, J., Kirkland, E., Lopez, A., Schulkin, J., \& Lynfield, R. (2003). Toxoplasmosis related knowledge and practices among pregnant women in the United States. Infect Dis Obstet Gynecol, 11, 139-145. http://dx.doi.org/10.1080/10647440300025512

Kapperud, G., Jenum, P. A., \& Stray-Pedersen, B. (1996). Risk factors for Toxoplasma gondii infection in pregnancy. Results of a prospective case-control study in Norway. Am J Epidemiol, 144, 405-412. http://dx.doi.org/10.1093/oxfordjournals.aje.a008942 
Kravetz, J. D., \& Federman, D. G. (2005). Prevention of toxoplasmosis in pregnancy: Knowledge of risk factors. Infect Dis Obstet Gynecol, 13(3), 161-165. http://dx.doi.org/10.1080/10647440500068305

Lopez, A., Dietz, V. J., Wilson, M., Navin, T. R., \& Jones, J. L. (2000). Preventing congenital toxoplasmosis. MMWR Recomm Rep, 49(RR-2), 59-68.

Nijem, K., \& Al-Amleh, S. (2009). Seroprevalence and associated risk factors of toxoplasmosis in pregnant women in Hebron district, Palestine. East Mediterr Health J, 15, 1279-1284.

Ogunmodede, F., Scheftel, J., Jones, J. L., \& Lynfield, R. (2005). Toxoplasmosis prevention knowledge among pregnant women in Minnesota. Min Med J, 88, 32-34.

Pappas, G., Roussos, N., \& Falagas, M. E. (2009). Toxoplasmosis snapshots: global status of Toxoplasma gondii seroprevalence and implications for pregnancy and congenital toxoplasmosis. Int J Parasitol, 39, 1385-1394. http://dx.doi.org/10.1016/j.ijpara.2009.04.003

Pawlowski, Z. S., Gromadecka-Sutkiewicz, M., Skommer, J., Paul, M., Rokossowski, H., Suchocka, E., \& Schantz, P. M. (2001). Impact of health education on knowledge and prevention behavior for congenital toxoplasmosis: the experience in Poznan, Poland. Health Educ Res, 16, 493-502. http://dx.doi.org/10.1093/her/16.4.493

Razzak, A. H., Wais, S. A., \& Saeid, A. Y. (2005). Toxoplasmosis: the innocent suspect of pregnancy wastage in Duhok, Iraq. East Medit Health J, 11(4), 625-632.

Tonkal, A. M. (2008). The PCR versus ELISA in diagnosis of human toxoplasmosis in Jeddah, Saudi Arabia. $J$. Egypt Soc. Parasitol, 38(3), 707-14.

Varella, I. S., Canti, I. C., Santos, B. R., Coppini, A. Z., Argondizzo, L. C., Tonin, C., \& Wagner, M. B. (2009). Prevalence of acute toxoplasmosis infection among 41,112 pregnant women and the mother-to-child transmission rate in a public hospital in South Brazil. Mem Inst Oswaldo Cruz, 104, 383-388. http://dx.doi.org/10.1590/S0074-02762009000200037

\section{Copyrights}

Copyright for this article is retained by the author(s), with first publication rights granted to the journal.

This is an open-access article distributed under the terms and conditions of the Creative Commons Attribution license (http://creativecommons.org/licenses/by/3.0/). 